EPiC Series in Built Environment
Volume 2, 2021, Pages 626-634
ASC 2021. 57th Annual Associated Schools
of Construction International Conference

\title{
Prescriptive Bio-Based Earth Mortar Composites as a Buffer for Internal Thermal Comfort
}

\author{
Abbie Romano, Ph.D, Michael Riley, PhD and Ana Bras, Ph.D. \\ Liverpool John Moores University \\ Liverpool, United Kingdom
}

To decarbonise the current building stock, action is required in order to utilise natural resources as retrofitting tools. This research paper uses bio-based insulation samples in combination with an earth mortar in order to create a hygric buffer to improve thermal comfort within residential properties and select the best performing bio-fibre. Three different bio-fibres were used (Saw Mill Residue and two different types of sheep wool: Wool 1 and Wool 2) in addition to 2 different mix designs and a plain control sample. Bio-fibres were characterised using SEM imaging to define surface morphology as an indication of the materials characteristics. Moisture buffering value (MBV) (where samples were exposed to step changes in relative humidity of $75 \%$ and $53 \%$ for 8 and 16 hours respectively) was also conducted to give a greater understanding of the dynamic way in which water is transported through the panel. Capillary action was also measured as an indication of the short, medium and long-term deformation water has on earthen-based construction. From 8 different mix designs, M1 SMR was selected for further experimentation.

Key Words: bio-based, earth construction, MBV, hygrothermal

\section{Introduction}

The European Union (E.U.) outlined within the Energy Performance Directive in 2018 - which would aim to renovate current building stocks to nearly or zero energy buildings (Housing Europe 2018). Whilst energy efficiency in buildings not only reduces the emissions to the environment on a European scale, it also aligns with the United Nations (U.N.) Sustainable Development Goals 11 and 13 (Di Foggia 2018). Important to understand that a 'one size fits all' approach is not suitable nationally let along internationally (Brás et al 2014; CAT 2018). A realistic and performance driven retrofitting tool that enable tailoring green materials for decarbonisation is essential to meet these targets (Kelly 2009). By utilising the natural world and manipulating their hygrothermal performance will enable the production of a relative humidity buffer as a retrofitting tool within residential properties. 
The use of bio-based fibres is highly environmentally beneficial due to being naturally occurring and having a relatively low environmental impact in comparison to other more widely used construction materials (such as steel or concrete) (Korjenic et al 2011; Peñaloza et al 2016) (Laborel-Préneron et al 2016). Intrinsically, bio-based materials have a high hygrothermal ability so are able to readily adsorb and desorb in to the local environment (Jones and Brischke 2017). Key factors when considering any renovation is the health and well-being of occupants but also its durability and life cycle of the product and how these materials are affected by hysteresis. This is particularly important when considering their use as a hygric buffer as a retrofitting tool.

Combining bio-based fibres with another material will require an equally 'hygrothermally active' material within a matrix in order to match and potentially enhance the performance of the fibres. The utilisation of earth within the built environment is used by 2.2 billion people (approximately $30 \%$ of the world's population) whom live in earth-based buildings (Costa et al 2016). Despite being so readily available, key issues with using earth is it being highly sensitive to deformation with water (Muller et al, 2016) due to its hydrophilic behaviour. Organised into 3 main categories of structural, environmental and chemical issues associated with using earth are demonstrated in Table 1.

Table 1.

Categories of earth deformation

\begin{tabular}{|c|c|c|c|}
\hline Structural & $\begin{array}{c}\text { Thermal } \\
\text { expansion/shrinkage } \\
\text { causing cracking }\end{array}$ & \multicolumn{2}{|c|}{ Water adsorption/absorption } \\
\hline Environmental & Weathering & $\begin{array}{c}\text { Poor construction/finish } \\
\text { quality }\end{array}$ & $\begin{array}{c}\text { Biological } \\
\text { susceptibility }\end{array}$ \\
\hline Chemical & Delamination/Detachment due to incompatibility & $\begin{array}{c}\text { Chemical } \\
\text { attack }\end{array}$ \\
\hline
\end{tabular}

These different types of deformation can occur within the short, medium and long term at a micro or nano scale to create macro-sized cracks. Due to the availability of this material, there will be significant variations in the material on a local, national and international basis. However, whilst traditionally seen as 'negative' characteristics, this paper will utilise earths ability to be highly deformable under water adsorption/absorption. This trait of Earth presents hygrothermal benefits to create a moisture buffering panel (Fratini et al., 2011).

This paper will aim to utilise bio-based fibres in an earth mortar composite for use within residential properties, to understand how they could potentially be implemented within different building fabrics.

\section{Materials}

\section{Earth}

The earth was sourced from Liverpool, North West England where the grain size distribution can be found within Figure 1. Obtained from a construction site at a depth of $1.5-2 \mathrm{~m}$, the earth was disaggregated and passed through a $2 \mathrm{~mm}$ sieve to remove any construction waste before being 
combined into the mix design. The lime utilised within this mix design is natural hydraulic lime which was supplied from a national builder's merchant.

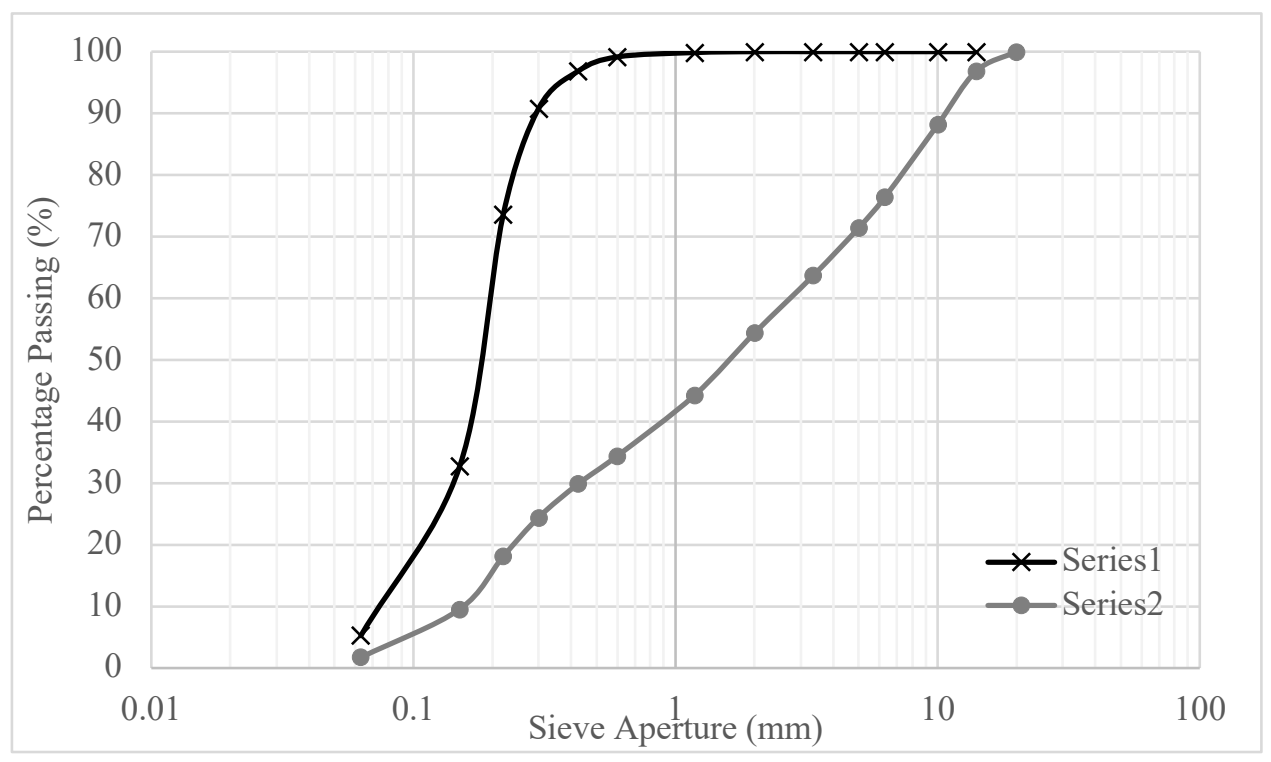

Figure 1. Grainsize Distribution Chart (as per 1015-1 (CEN, 1999a)

\section{Bio-Fibres}

The different bio-fibres within this paper are all available as bio-based insulation on the market within the United Kingdom, those used are: Saw Mill Residue (SMR), Wool 1 (WL1), Wool 2 (W2) and a plain (PL) sample.

\section{Methods}

Formulation

Each mix was created in accordance with EN 1015-2 (CEN, 1999b), mixing all dry ingredients (including earth and bio-fibres) are combined in order to homogenise then water is added. To avoid flocculation, fibres were pulled apart and to calibrate the consistency of the composite each mix was given a fixed consistence of 150-160mm (as per EN 1015-3 (CEN, 1999c)). The mix design for Mix 1 and Mix 2 can be found in Table 2. Prismatic $(40 \mathrm{~mm} \times 40 \mathrm{~mm} \times 160 \mathrm{~mm})$ and MBV square $(100 \mathrm{~mm} \times$ $100 \mathrm{~mm} \times 35 \mathrm{~mm}$ ) were cast. 
Table 2.

Mix design properties for Mix 1(M1) and Mix 2 (M2) (by mass).

\begin{tabular}{|c|c|c|c|c|}
\hline Mix Design ID & Lime & Earth & Sand & Water \\
\hline M1 & 1 & 0.1 & 8.6 & 2.4 \\
\hline M2 & 1 & 0.3 & 10.3 & 2.7 \\
\hline
\end{tabular}

\section{Curing}

Samples were cured for 14 days within their moulds and then de moulded and elevated to ensure samples could dry on all sides simultaneously. The curing conditions were that of the laboratory at approximately $21 \mathrm{oC}$ and $54 \%$ relative humidity.

\section{Methods}

\section{Scanning Electron Microscopy (SEM)}

Investigating the surface morphology of the bio-fibres gives an indication of the material characteristics, which was done by coating the samples in a Gold spluttering and observed using a Scanning Electron Microscope Inspect S. Understanding the formation under a microscope could demonstrate a further understanding of the material's inherent properties and surface morphology.

\section{Moisture Buffering Value (MBV)}

As a method of demonstrating a materials ability to adsorb/desorb water with a differing hygrothermal environment, MBV is calculated for each sample. Exposed to 15, 24-hour cyclical step change of 75\% for 8 hours and $53 \%$ for 16 hours at $23^{\circ} \mathrm{C}$ in conformity with NORDTEST protocol (Rode et al 2005) in ISO 21453 (ISO 2008) in order to replicate a U.K. household (as seen in Romano et al, 2019). The calculation of this is in Equation 1. This parameter is considered the most significant characteristic as it will link to the efficiency of the panel itself.

$$
\operatorname{MBV}=\frac{\mathrm{m}_{\mathrm{a}}-\mathrm{m}_{\mathrm{d}}}{\mathrm{A} \Delta \varphi}
$$

Where:

$\mathrm{m}_{\mathrm{a}}=$ Mass of sample at end of moisture adsorption stage $(\mathrm{g})$

$\mathrm{m}_{\mathrm{d}}=$ Mass of sample at end of moisture desorption stage $(\mathrm{g})$

$\mathrm{A}=$ Exposed surface area of sample $\left(\mathrm{m}^{2}\right)$

$\Delta \varphi=$ Difference in RH between adsorption and desorption stage (\%)

\section{Capillary Action}

By understanding the way in which materials initially adsorb water and the rate in which they retain it is a particularly useful characteristic for this hygrothermal buffer. Prismatic samples were submerged and measurements taken in line with EN 1015-18: 2002 (CEN,2002). 


\section{Results and Discussion}

\section{SEM}

The SEM images for just the bio-fibres is demonstrated within Figures 2a-c. These bio-fibres demonstrate two differing morphology patterns from these bio-based materials. Whilst all three samples show a fibrous and multidimensional microstructure it is evident that SMR has much larger fibres whilst W1 and W2 have smaller diameter of individual fibres but there is a much greater quantity.

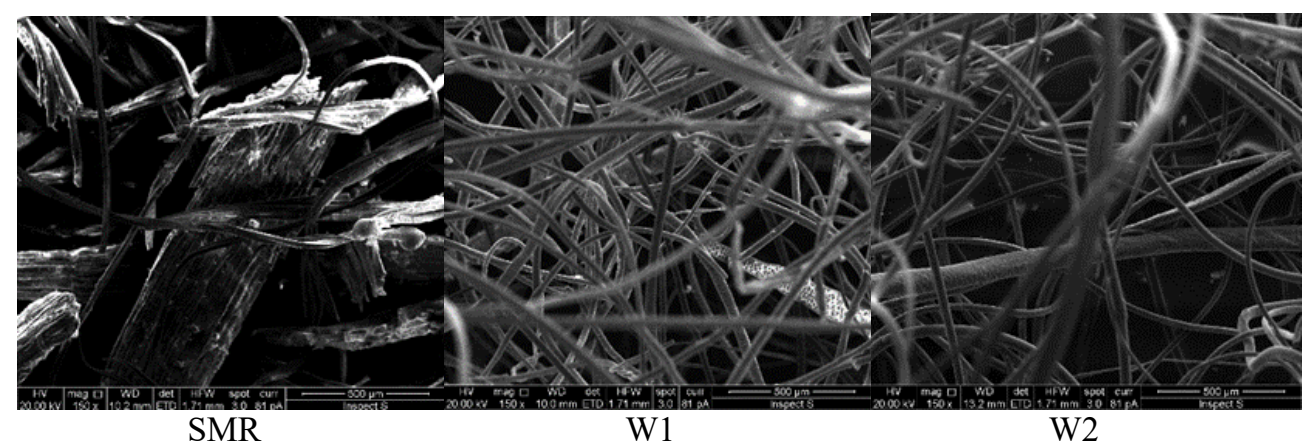

Figure 2. SEM Bio-fibres

\section{$M B V$}

The MBV for the samples is shown within Table 3. Identifying the way in which a sample efficiency and effectively exchanges water vapour is integral to this research as it identifies the moisture transport within each mix. Within table 3 it is evident that the mixes do not vary sufficiency in order to make a differentiation between the two mixes.

Table 3.

MBV classification for mix designs.

\begin{tabular}{|c|c|c|c|}
\hline \multirow{2}{*}{ Mix Design } & Bio-Fibre & $\begin{array}{c}\text { MBV } \\
\left(\mathbf{g} / \mathbf{m}^{\mathbf{2}} \mathbf{\%} \mathbf{R H}\right)\end{array}$ & $\begin{array}{c}\text { MBV Classification } \\
\text { (as per (Rode et al 2005) }\end{array}$ \\
\hline \multirow{3}{*}{1} & NF & 1.015 & Good \\
\cline { 2 - 4 } & W1 & 1.394 & Good \\
\cline { 2 - 4 } & W2 & 1.136 & Good \\
\cline { 2 - 4 } & SMR & 1.182 & Good \\
\hline \multirow{2}{*}{2} & NF & 1.000 & Good \\
\cline { 2 - 4 } & W1 & 1.091 & \\
\hline
\end{tabular}




\begin{tabular}{|c|c|c|c|}
\hline \multirow{2}{*}{} & W2 & 1.121 & Good \\
\cline { 2 - 4 } & SMR & 1.227 & Good \\
\hline
\end{tabular}

As the two mix designs have the same exposed surface area, the mass change graph per $\mathrm{m}^{2}$ can be utilised to demonstrate the mass variation for each cycle - the final 2 cycles are demonstrated within Figure 3 and 4. Even when bound within an earth mortar matrix, bio-fibres are able to act hygrothermally and after 15 cycles are affected by hysteresis. M1 SMR has a clear high adsorption and is able to desorb to the approximate same mass as the start of the cycle. M1 W1 and M1 W2 have an initial high adsorption, but are unable to desorb equivalent gain.

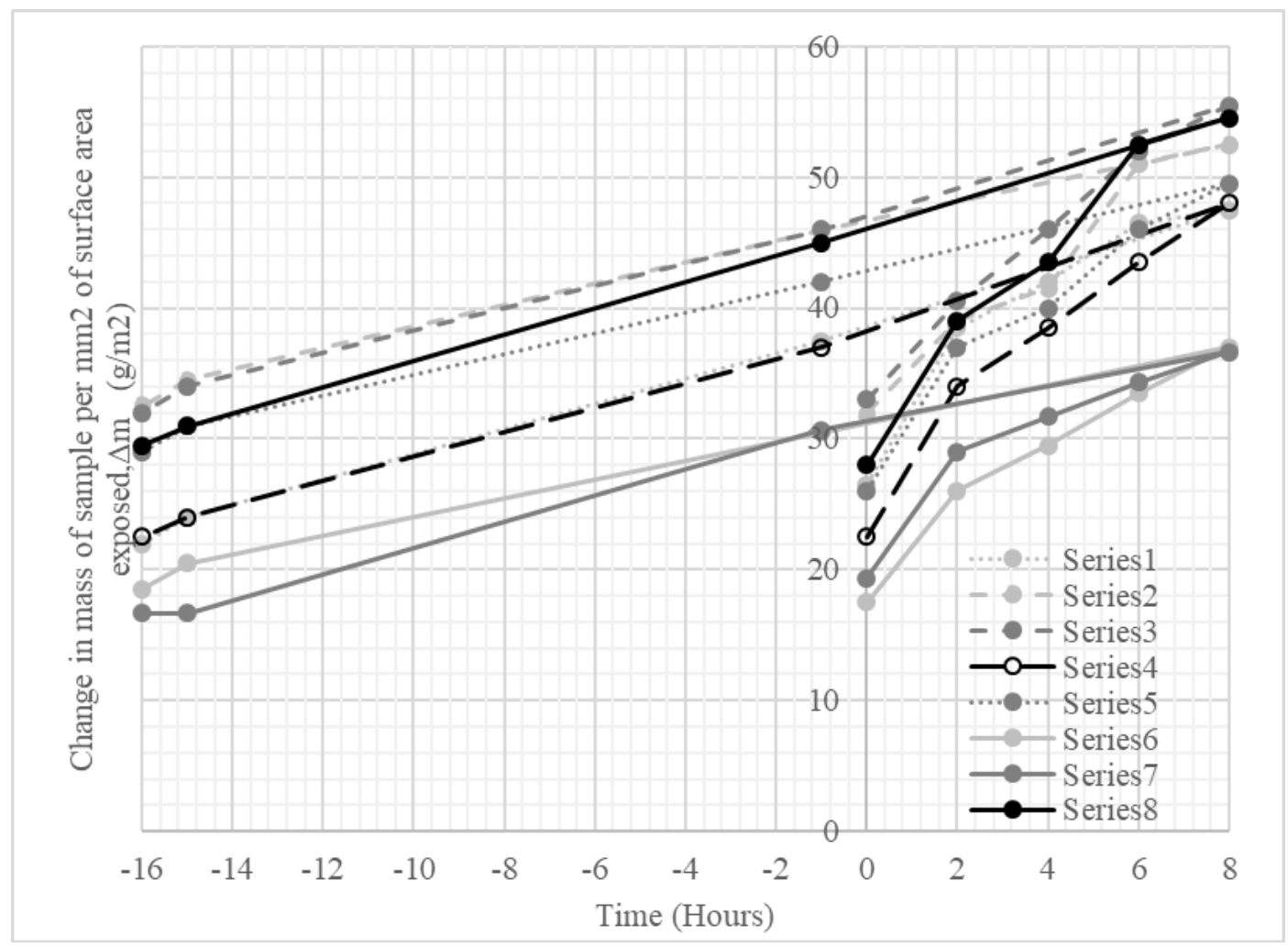

Figure 3. Adsorption/Desorption graph for all earth mortar samples after 14, 24 hour cycles. 


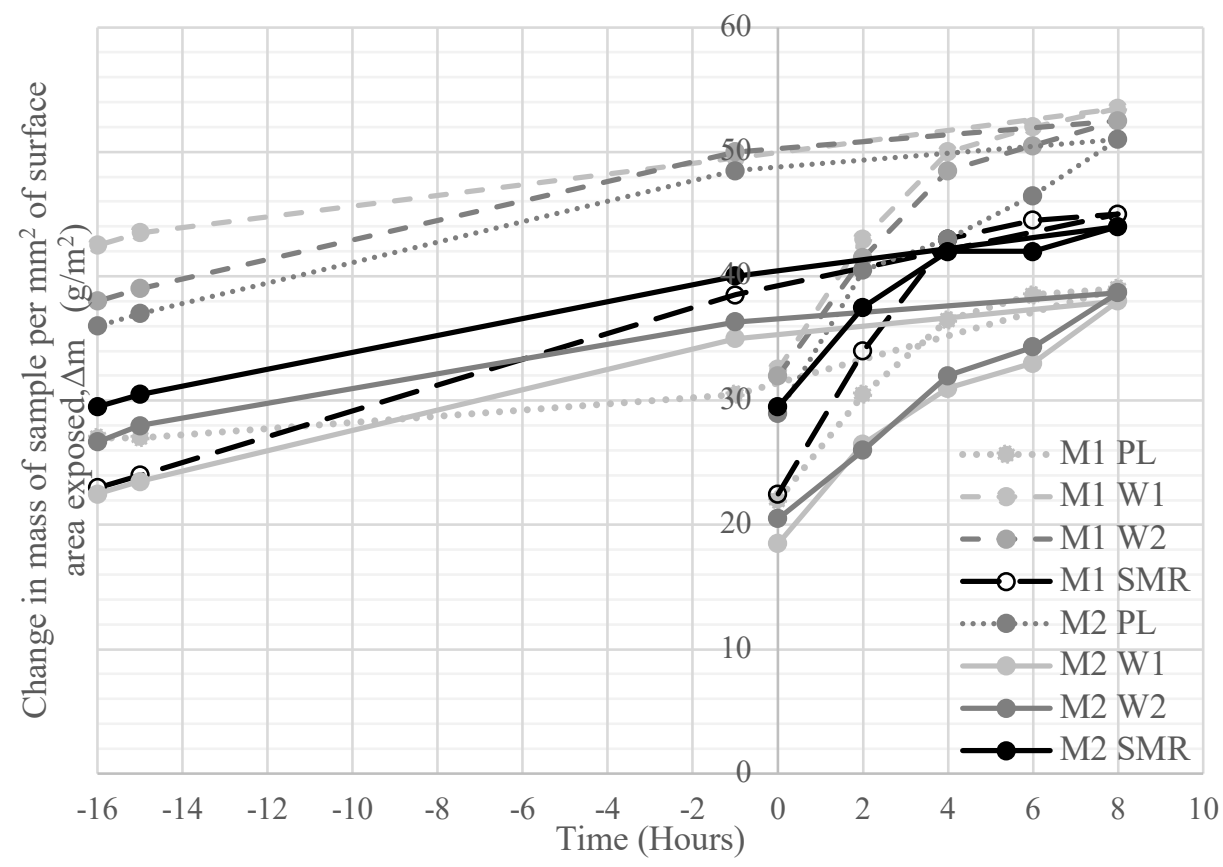

Figure 4.Adsorption/Desorption graph for all earth mortar samples after 15, 24 hour cycles

When considering the different building fabrics that exist within the faculty campus at LJMU where full size homes built to 1920s,1970s and 2010s building standards it is evident that these environments will have a different hygrothermal requirement. The different building fabrics are demonstrated within Figures 5a-c.

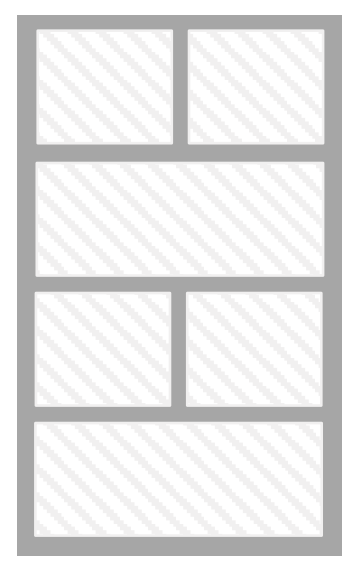

Figure 5a.

$1920 \mathrm{~s}$

Solid masonry wall

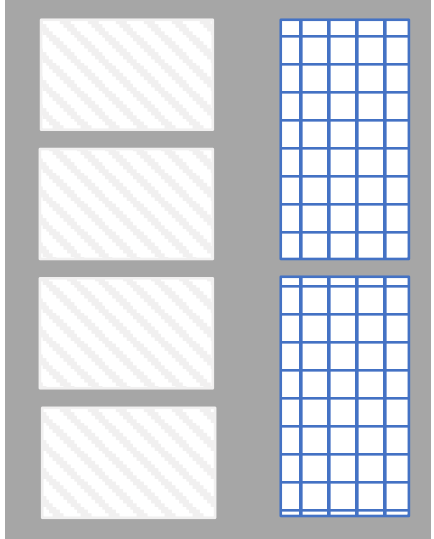

Figure $5 b$. 1970s

Outer facing brick, $50 \mathrm{~mm}$ clear cavity, lightweight concrete inner

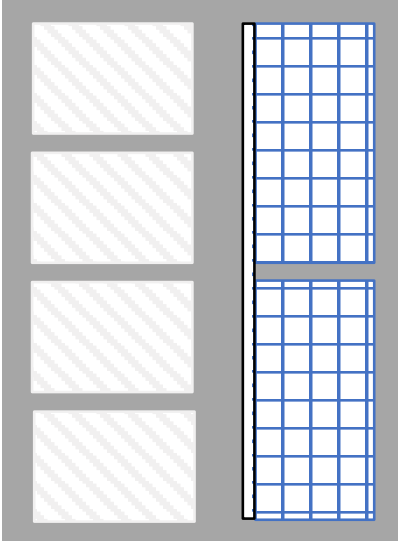

Figure 5c. $2010 \mathrm{~s}$

Outer facing brick $50 \mathrm{~mm}$ clear cavity, $40 \mathrm{~mm}$ insulation board, medium 
Different building fabrics will have different moisture levels due to advances in house building technology. Bio-based fibres and composites have the potential to be prescriptive as a 'one size fits all' approach for moisture buffering panels cannot be implemented in order to act as a retrofitting tool.

\section{Capillary Action}

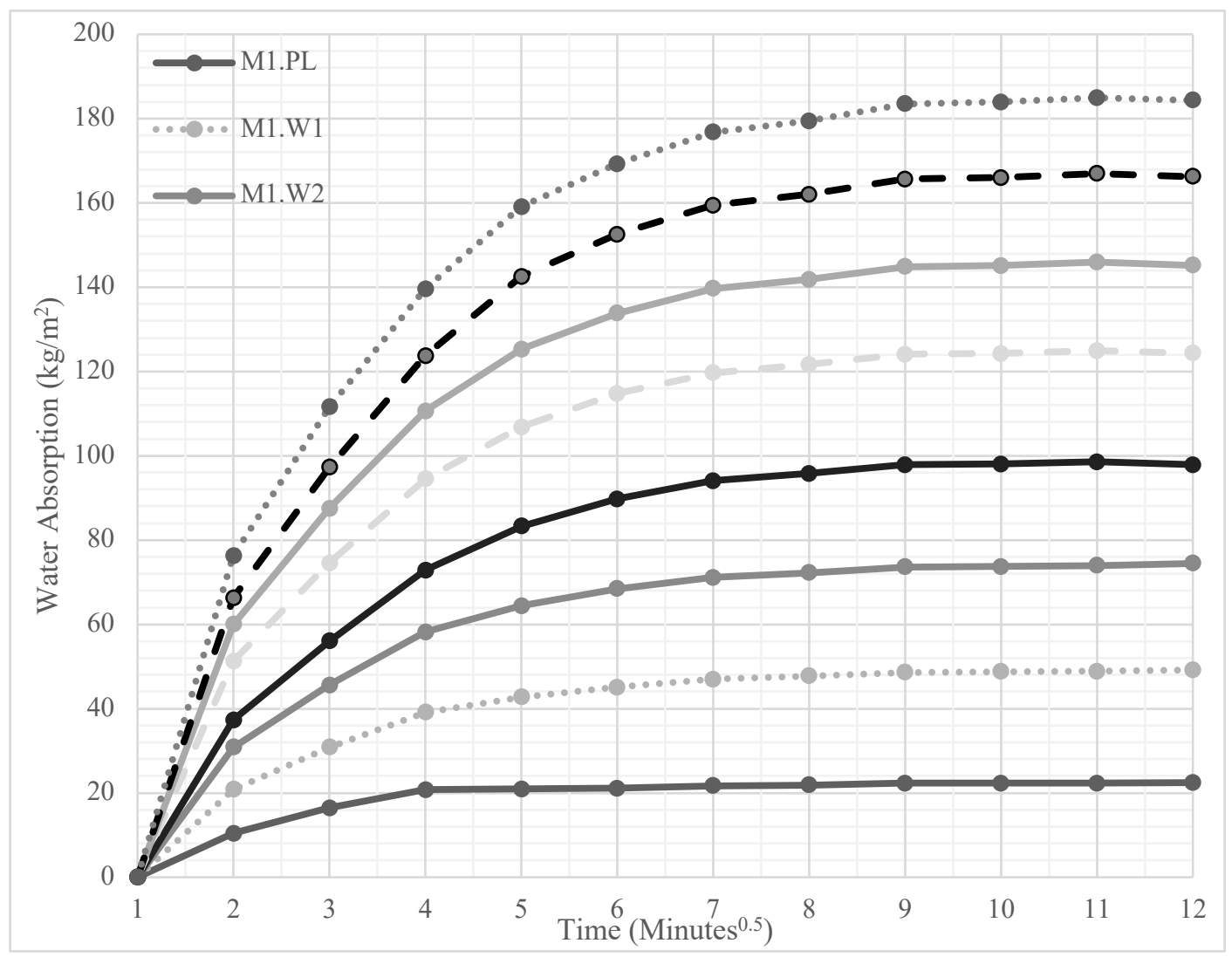

Figure 6. Capillary action curve for earth mortar samples

A key element of deformation for earthen based materials is due its high affinity for water. Figure 6 highlights the initial adsorption and sustained absorption (plateau region). Initially, high water adsorption is from M2 W1 is also sustained throughout the experiment compared with M1 PL with the smallest initial and constant water adsorption., Mix $1 \mathrm{WL} 1$ had the lowest initial water adsorption and sustained water adsorption. Overall, all M1 samples have a lower initial and continual water adsorption in comparison to M2. Despite the aim of this paper to create a panel which will remain indoors, due to the low durability of earthen construction, the long-term adsorption and its effect on service life must also be considered.

\section{Conclusion}

To produce a bio-based passively controlled thermal management panel the best moisture buffering samples should be selected. Surface morphology demonstrates that SMR although similar to W1 and W2 has larger exposed surface than the woollen sample. From these experiments it is evident that there cannot be one material to utilise as a retrofitting tool due to different fabrics will have different 
hygrothermal demands on the panel. M1 SMR was able to remain hygrothermally effective and efficient after over 15, 24 hour cycles by comparison to the other mix designs, this mix design will be selected into other to further enhance the creation of the RH buffering panel.

\section{References}

Brás, A.; Gonçalves, F; Faustino, P, 2014. Economic evaluation of the energy consumption and thermal passive performance of Portuguese dwellings. Energy and Buildings, 76, 304-315.

CAT. 2018. Climate Action Tracker: Scaling up climate action - Key opportunities for transitioning to a zero emissions society.CAT Scaling Up Climate Action - European Union.

CEN (1999a) BS EN 1015-1:1999 - Methods of test for mortar for masonry. Determination of particle size distribution (by sieve analysis).

CEN (1999b) BS EN 1015-2:1999 - Methods of test for mortar for masonry. Bulk sampling of mortars and preparation of test mortars.

CEN (1999c) BS EN 1015-3:1999 - Methods of test for mortar for masonry. Determination of consistence of fresh mortar (by flow table).

CEN (2002) BS EN 1015-18:2002 - Methods of test for mortar for masonry. Determination of water absorption coefficient due to capillary action of hardened mortar.

Costa, C., Rocha, F. and Velosa, A. (2016) Sustainability in earthen heritage conservation.

Di Foggia, G. 2018. Energy efficiency measures in buildings for achieving sustainable development goals. Heliyon, 4 (11), e00953.

Fratini, F., Pecchioni, E., Rovero, L. and Tonietti, U. (2011) The earth in the architecture of the historical centre of Lamezia Terme (Italy): Characterization for restoration. Applied Clay Science, 53 (3), 509-516.

Housing Europe .2018. Decarbonisation of the building stock: a two-front battle. Energy.

ISO, 24353. (2008) Hygrothermal performance of building materials and products - Determination of moisture adsorption/desoption properties in response to humidity.

Jones, D. and Brischke, C. (2017) Performance of Bio-based Building Materials. Elsevier Science. Kelly, M.J. 2009. Retrofitting the existing UK building stock. Building Research \& Information, 37 (2), 196-200.

Korjenic, A., Zach, J. and Hroudová, J. (2016) The use of insulating materials based on natural fibers in combination with plant facades in building constructions. Energy and Buildings, 116, 45-58.

Laborel-Préneron, A., Aubert, J.E., Magniont, C., Tribout, C. and Bertron, A. (2016) Plant aggregates and fibers in earth construction materials: A review. Construction and Building Materials, 111 (Supplement C), 719-734.

Müller, U., Miccoli, L. and Fontana, P. (2016) Development of a lime based grout for cracks repair in earthen constructions. Construction and Building Materials, 110, 323-332.

Peñaloza, D., Erlandsson, M. and Falk, A. (2016) Exploring the climate impact effects of increased use of bio-based materials in buildings. Construction and Building Materials, 125, 219-226.

Rode, C., Peuhkuri, R.H., Hansen, K.K., Time, B., Svennberg, K., Arfvidsson, J. and Ojanen, T. (2005) NORDTEST Project on Moisture Buffer Value of Materials. 47-52.

Romano, A., Bras, A., Grammatikos, S., Shaw, A. and Riley, M. (2019) Dynamic behaviour of biobased and recycled materials for indoor environmental comfort. Construction and Building Materials, $211,730-743$ 